\title{
Erratum to: The clinical and cost effectiveness of group art therapy for people with non- psychotic mental health disorders: a systematic review and cost-effectiveness analysis
}

Lesley Uttley ${ }^{*}$, Matt Stevenson, Alison Scope, Andrew Rawdin and Anthea Sutton

Unfortunately, the original version of this article [1] contained an error. An entry was incorrect Uttley et al. in the reference list. The correct reference can be found below:

Uttley L, Scope A, Stevenson M, Rawdin A, Taylor Buck E, Sutton A, et al. Systematic review and economic modelling of the clinical effectiveness and cost-effectiveness of art therapy among people with non-psychotic mental health disorders. Health Technol Assess 2015;19(18).

Received: 7 September 2015 Accepted: 7 September 2015

Published online: 10 September 2015

\section{Reference}

1. Uttley L, Stevenson M, Scope A, Rawdin A, Sutton A. The clinical and cost effectiveness of group art therapy for people with non-psychotic mental health disorders: a systematic review and cost-effectiveness analysis. BMC Psychiatry. 2015;15:151.

* Correspondence: l.uttley@sheffield.ac.uk

School of Health and Related Research (ScHARR), University of Sheffield,

Regent Court, 30 Regent Street, Sheffield S1 4DA, UK 